J. Dairy Sci. 92:952-959

doi:10.3168/jds.2008-1549

(C) American Dairy Science Association, 2009.

\title{
Analytical specificity and sensitivity of a real-time polymerase chain reaction assay for identification of bovine mastitis pathogens
}

\author{
M. T. Koskinen, ${ }^{* 1}$ J. Holopainen, ${ }^{\star}$ S. Pyörälä,† P. Bredbacka, ${ }^{*}$ A. Pitkälä,‡ H. W. Barkema,§ R. Bexiga,\# \\ J. Roberson, || L. Sølverød, \\ ${ }^{*}$ Finnzymes Diagnostics, Keilaranta 16A, 02150 Espoo, Finland \\ †University of Helsinki, Faculty of Veterinary Medicine, Department of Production Animal Medicine, 04920 Saarentaus, Finland \\ ¥Finnish Food Safety Authority Evira, 00790 Helsinki, Finland \\ §Department of Production Animal Health, Faculty of Veterinary Medicine, University of Calgary, T2N 4N1 Canada \\ \#Microbiologia e Imunologia, CIISA/Faculdade de Medicina Veterinária, 1300-477 Lisboa, Portugal \\ \|Veterinary Medical Teaching Hospital, Department of Clinical Sciences, Kansas State University, Manhattan 66506 \\ ITINE Produsentrådgiving, Mastittlaboratoriet, 6402 Molde, Norway \\ ${ }^{* *}$ Department of Animal Pathology, Hygiene and Health, University of Milan, 20133 Milan, Italy \\ ††CanWest DHI, Guelph, Ontario, N1K 1E5 Canada
}

\begin{abstract}
Intramammary infection (IMI), also known as mastitis, is the most frequently occurring and economically the most important infectious disease in dairy cattle. This study provides a validation of the analytical specificity and sensitivity of a real-time PCR-based assay that identifies 11 major pathogen species or species groups responsible for IMI, and a gene coding for staphylococcal $\beta$-lactamase production (penicillin resistance). Altogether, 643 culture isolates originating from clinical bovine mastitis, human, and companion animal samples were analyzed using the assay. The isolates represented 83 different species, groups, or families, and originated from 6 countries in Europe and North America. The analytical specificity and sensitivity of the assay was $100 \%$ in bacterial and $\beta$-lactamase identification across all isolates originating from bovine mastitis $(\mathrm{n}=454)$. When considering the entire culture collection (including also the isolates originating from human and companion animal samples), 4 Streptococcus pyogenes, 1 Streptococcus salivarius, and 1 Streptococcus sanguis strain of human origin were identified as Streptococcus uberis, and 3 Shigella spp. strains were identified as Escherichia coli, decreasing specificity to 99\% in Strep. uberis and to $99.5 \%$ in E. coli. These false-positive results were confirmed by sequencing of the $16 \mathrm{~S}$ rRNA gene. Specificity and sensitivity remained at $100 \%$ for all other bacterial targets across the entire culture collection. In conclusion, the real-time PCR assay shows excellent analytical accuracy and holds much promise for use in routine bovine IMI testing programs. This study provides the basis for evaluating the assay's
\end{abstract}

Received July 14, 2008.

Accepted November 4, 2008.

${ }^{1}$ Corresponding author: mikko.koskinen@finnzymes.fi diagnostic performance against the conventional bacterial culture method in clinical field trials using mastitis milk samples.

Key words: bovine intramammary infection, realtime PCR, validation

\section{INTRODUCTION}

Intramammary infection, also commonly known as mastitis, is the most frequently occurring and economically the most important infectious disease in dairy cattle (Halasa et al., 2007). Mastitis is usually caused by one primary pathogen (Watts and Yancey, 1994), and approximately 10 bacterial species or species groups account for more than $95 \%$ of all clinical and subclinical infections (Makovec and Ruegg, 2003; Tenhagen et al., 2006; Bradley et al., 2007; Koivula et al., 2007). Reliable identification of the pathogens responsible for IMI is one of the cornerstones for controlling the disease and for targeting antimicrobial therapy (National Mastitis Council, 1996).

Bacterial culture has long served as the golden standard for mastitis testing (National Mastitis Council, 1996, 1999, 2004). However, several studies have suggested that PCR-based assays could be useful to complement or to replace conventional bacteriological IMI identification methods (Riffon et al., 2001; Phuektes et al., 2003; Gillespie and Oliver, 2005). Among the primary arguments in favor of PCR assays are their short throughput times, potential for objective and user-independent identification of bacteria and antibiotic resistance genes, and ability for sensitive detection of growth-inhibited and dead bacteria. In addition to possibly decreasing the rate of false-negative results (up to $50 \%$ of clinical mastitis samples harbor no growth in bacterial culture; Makovec and Ruegg, 2003), identification of nonviable bacteria would also 
Table 1. Analytical sensitivity and specificity results for the bacterial targets of the PathoProof Mastitis PCR Assay ${ }^{1}$

\begin{tabular}{|c|c|c|c|c|c|c|}
\hline $\begin{array}{l}\text { Bacterial target of the assay and (in parentheses) } \\
\text { species prevalence across } 77,051 \text { clinical } \\
\text { and subclinical mastitis samples }{ }^{2}\end{array}$ & \multicolumn{4}{|c|}{$\mathrm{n}$} & $\begin{array}{c}\text { Sensitivity } \\
\%\end{array}$ & $\begin{array}{c}\text { Specificity } \\
\%\end{array}$ \\
\hline Staphylococcus spp. ${ }^{3}(21.12 \%)^{4}$ & $246(306)$ & $0(0)$ & $208(337)$ & $0(0)$ & $100(100)$ & $100(100)$ \\
\hline Streptococcus agalactiae $(0.17 \%)$ & $22(23)$ & $0(0)$ & $432(620)$ & $0(0)$ & $100(100)$ & $100(100)$ \\
\hline Streptococcus dysgalactiae (8.26\%) & $32(32)$ & $0(0)$ & $422(611)$ & $0(0)$ & $100(100)$ & $100(100)$ \\
\hline Enterococcus faecalis, Enterococcus faecium $(2.14 \%)^{5}$ & $39(52)$ & $0(0)$ & $415(591)$ & $0(0)$ & $100(100)$ & $100(100)$ \\
\hline Corynebacterium bovis $(2.24 \%)^{6}$ & $8(8)$ & $0(0)$ & $446(635)$ & $0(0)$ & $100(100)$ & $100(100)$ \\
\hline Arcanobacterium pyogenes, Peptostreptococcus indolicus $(1.23 \%)^{7}$ & $8(8)$ & $0(0)$ & $446(635)$ & $0(0)$ & $100(100)$ & $100(100)$ \\
\hline Serratia marcescens $(0.84 \%)^{8}$ & $4(8)$ & $0(0)$ & $450(635)$ & $0(0)$ & $100(100)$ & $100(100)$ \\
\hline Klebsiella oxytoca, Klebsiella pneumonia $(0.84 \%)^{8}$ & $15(22)$ & $0(0)$ & $439(621)$ & $0(0)$ & $100(100)$ & $100(100)$ \\
\hline$\beta$-lactamase gene & $72(72)$ & $0(0)$ & $77(77)$ & $0(0)$ & $100(100)$ & $100(100)$ \\
\hline
\end{tabular}

${ }^{1}$ Sample numbers and sensitivity and specificity percentages are indicated for strains originating from clinical samples of bovine mastitis $(\mathrm{n}=$ $454)$ and, in parentheses, for the entire data set, including additional clinical samples from dogs $(\mathrm{n}=49)$ and humans $(\mathrm{n}=140)$.

${ }^{2}$ According to Koivula et al. (2007). In addition to the listed prevalence percentages, $28.60 \%$ of the samples were culture-negative and $4.07 \%$ were considered contaminated.

${ }^{3}$ The Staph. spp. group included isolates with growth of Staph. aureus, Staph. intermedius and the following coagulase negative staphylococci identified using API: Staph. chromogenes, Staph. epidermidis, Staph. hemolyticus, Staph. saprohyticus, Staph. simulans, Staph. warneri and Staph. xylosus.

${ }^{4}$ Includes only CNS.

${ }^{5}$ Includes all gram-positive catalase-negative cocci.

${ }^{6}$ Includes all Corynebacterium spp.

${ }^{7}$ Includes only $A$. pyogenes, as the prevalence study did not include $P$. indolicus $(P$. indolicus is an anaerobic mastitis pathogen which is not identified in routine mastitis testing programs).

${ }^{8}$ Includes all Enterobacteriaceae.

enable integration of IMI diagnostics into somatic cell count measurement and dairy herd improvement programs making use of bronopol-preserved composite milk samples. A modification of PCR, known as realtime PCR, may offer further benefits to quantify the microbial load in milk samples, to facilitate automation of the laboratory workflow, and to reduce the risk of PCR cross-contaminations in the laboratory (Bustin, 2004).

Development of a PCR test capable of complementing or replacing conventional methods in mastitis testing presents a challenge because of the large number of pathogens responsible for IMI, many of which are genetically closely related. Furthermore, milk contains PCR-inhibiting substances and an assay designed for use with mastitic milk must include dedicated DNA extraction protocols and reagents to provide high quality results. Among the first commercially available PCR-based mastitis tests, developed for use with milk samples and including all reagents for DNA extraction and real-time PCR, is the PathoProof Mastitis PCR Assay (Finnzymes Oy, Espoo, Finland). The assay is performed directly from raw or preserved milk, without the need for bacterial culturing, and it identifies a total of 11 mastitis-causing bacterial species or species groups and the $\beta$-lactamase gene (the blaZ gene) responsible for staphylococcal penicillin resistance. The bacteria targeted by the assay include Staphylococcus aureus, CNS, Streptococcus agalactiae, Streptococcus dysgalactiae, Streptococcus uberis, Escherichia coli, Enterococcus spp., Klebsiella spp., Corynebacterium bovis, Serratia marcescens, Arcanobacterium pyogenes, and Peptostreptococcus indolicus. Based on several North American and European prevalence studies, these species include all of the most relevant and frequently occurring bacteria isolated from subclinical and clinical mastitis samples (e.g., Makovec and Ruegg, 2003; Tenhagen et al., 2006; Koivula et al., 2007; Table 1).

Identification of the mastitis pathogens from milk based on the conventional culture methods can provide false bacterial identifications in routine test laboratories. For example, based on a European proficiency testing program, it was reported that the overall rate of erroneously identified bacteria ranged between 9 and $37 \%$ across the different mastitis culture laboratories (Pitkälä et al., 2005). Such a low level of specificity, coupled with up to $50 \%$ of results with no growth in bacterial culture (Makovec and Ruegg, 2003), presents a severe challenge for comparing the true performance of any new technology against the existing routinely used method. Therefore, we provide here the first analytical specificity and sensitivity validation of the PathoProof 
Mastitis PCR Assay using well-characterized (e.g., by DNA sequencing) culture isolates obtained from bacterial culture collections. This study provides the basis for evaluating the PCR assay's diagnostic performance against the routinely used bacterial culture based methods in clinical field trials using mastitis milk samples.

\section{MATERIALS AND METHODS}

\section{Bacterial Culture Isolates}

A total of 643 bacterial isolates, representing 83 different species or species groups, were available for this study (supplementary material). The bacteria were acquired from several commercial and noncommercial culture collections. The cultures had been isolated in quarter milk samples from cows having clinical mastitis $(\mathrm{n}=454)$ or in clinical companion animal $(\mathrm{n}=49)$, or clinical human samples $(\mathrm{n}=140)$. The cultures included 525 isolates representing the target bacteria of the assay and 118 isolates of phylogenetically closely related nontarget species (supplementary material; Table 1 available online: http://jds.fass.org/content/vol92/issue3/). The isolates were obtained from a broad geographical area, originating from Canada $(\mathrm{n}=56)$, Finland $(\mathrm{n}=$ $377)$, Norway $(\mathrm{n}=46)$, Italy $(\mathrm{n}=69)$, Portugal $(\mathrm{n}=$ $67)$, and the United Kingdom $(\mathrm{n}=28)$. The cultures were stored in glycerol, peptone water, on agar plates, in tubes with nutrient broth, or in lyophilized form.

The culture providers had identified the isolates to their species or species group levels as accurately as conveniently possible. Many of the culture providers were national or international reference laboratories. For example, all of the cultures originating from the United Kingdom (supplementary information) were provided by the Department for Environment, Food and Rural Affairs, an organization responsible for international animal pathogen proficiency testing programs in the European Union, including an extensive mastitis proficiency testing program. For the cultures isolated in mastitic milk, National Mastitis Council standards were followed by highly experienced operators and for all samples in the species identification (Hogan et al. 1999). When the National Mastitis Council standards were not applicable for reliable identification of some species or species groups, several additional methods were used by the culture providers. These complementary methods included DNA sequencing of the 16S rRNA gene, pulse-field gel electrophoresis, and biochemical tests (e.g., API tests, bioMerieux, Marcy l'Etoile, France).

A proportion of the staphylococcal isolates used in this study $(\mathrm{n}=149)$ were included in an earlier comparative study of different $\beta$-lactamase identification methods
(Pitkälä et al., 2007). These samples included 77 Staph. aureus, 49 Staphylococcus intermedius, and 23 isolates of CNS. The Staph. aureus and CNS isolates originated from cows with IMI, and the Staph. intermedius strains were isolated from clinical samples obtained from dogs (Pitkälä et al., 2007). Based on the PCR test used as a gold standard by Pitkälä et al. (2007), 72 of the isolates were $\beta$-lactamase positive and 77 were negative. These isolates were used for validating the analytical specificity and sensitivity of the real-time PCR assay in detection of the blaZ gene.

\section{DNA Extraction and Real-Time PCR}

DNA was extracted from the bacterial isolates and the PCR reactions were performed using the reagents and protocol instructions included in the PathoProof Mastitis PCR Assay (Finnzymes Oy). Either $200 \mu \mathrm{L}$ of liquid culture/storage medium or a loopful of colonies from the agar plates was used as the starting material for DNA extraction. The DNA extraction protocol involved the following main steps:

1) an enzymatic lysis, disrupting the somatic cells present in mastitic milk;

2) a centrifugation, separating the bacterial cells from the lysed somatic cells and from many PCR-inhibiting substances present in milk, including fat;

3) an enzymatic lysis, disrupting the cell walls of gram-positive and gram-negative bacteria;

4) magnetic bead-based DNA purification and elution of bacterial DNA.

The assay's protocol involved 4 separate multiplex real-time PCR reactions, each of which targeted 3 bacterial species or species groups, as follows:

- Reaction 1: Staphylococcus aureus, Enterococcus spp. (including E. faecalis and E. faecium), and Corynebacterium bovis;

- Reaction 2: Escherichia coli, Strep. dysgalactiae, and $\beta$-lactamase penicillin resistance gene (blaZ);

- Reaction 3: Staphylococcus spp. (including Staph. aureus, Staph. intermedius and at least the following CNS: Staph. chromogenes, Staph. epidermidis, Staph. hemolyticus, Staph. saprohyticus, Staph. simulans, Staph. warneri, and Staph. xylosus), Strep. agalactiae, and Strep. uberis;

- Reaction 4: Arcanobacterium pyogenes and Peptostreptococcus indolicus, Klebsiella spp. (including K. oxytoca and K. pneumonia), and Serratia marcescens. 
Hence, the final result of a sample was a combination of the results from the above-mentioned 4 different real-time PCR reactions. In addition, each of the 4 realtime PCR reactions included an internal amplification control (IAC), composed of a 93-bp fragment of lambda-DNA $\left(10^{6}, 10^{5}, 10^{4}\right.$, and $10^{3}$ copies of the lambdaDNA fragment was included in reactions $1,2,3$, and 4 , respectively). The assay identified Staphylococcus spp., Enterococcus spp. and Klebsiella spp. to their species group levels; for example, E. faecalis and E. faecium were identified in the same real-time PCR reaction and instrument channel. Furthermore, A. pyogenes and $P$. indolicus were identified in the same real-time PCR reaction and channel.

The PCR reactions were set up by combining $5 \mu \mathrm{L}$ of the extracted DNA with $10 \mu \mathrm{L}$ of $2 \times$ Master Mix (including $9.0 \mathrm{mM}$ of $\mathrm{MgCl}_{2}, 0.4$ to $0.8 \mathrm{mM}$ of deoxynucleoside triphosphates and hot-start DNA polymerase in an optimized buffer having a $\mathrm{pH}$ of 8.5) and $5 \mu \mathrm{L}$ of the reaction-specific Primer Mix 1, 2, 3, or 4 (including species-specific primers and probes for the bacterial targets and the IAC, as well as IAC DNA). The following real-time PCR instruments were used for analyzing the culture isolates: ABI 7500 Fast Real-Time PCR System (Applied Biosystems Inc., Foster City, CA), Bio-Rad Chromo 4 (Bio-Rad Laboratories Inc., Hercules, CA), and Stratagene Mx Pro 3000P (Agilent Technologies Inc., Santa Clara, CA). The thermal cycling protocols were identical for all of the real-time PCR instruments, involving a $10 \mathrm{~min}$ predenaturation at $95^{\circ} \mathrm{C}$ and 40 cycles of $5 \mathrm{~s}$ denaturation at $95^{\circ} \mathrm{C}$ and $60 \mathrm{~s}$ annealing at $60^{\circ} \mathrm{C}$. The plate reads were always completed following the annealing step of the 2-step PCR protocol.

Real-time PCR fluorescence threshold settings were adjusted according to the assay's User Manual and Amplification Standard, which included control DNA in $10^{5}$ genome copies per microliter for each bacterial target. Scoring a reaction positive or negative for a target was based on obtaining a cycle threshold $(\mathbf{C t})$ value of below or above 37, respectively. The Ct cutoff value of 37 was chosen because obtaining a 3-cycle difference in target $\mathrm{Ct}$, in comparison to the negative control Ct, is the generally accepted norm for reliable separation of a true positive signal from a contamination (Bustin, 2004); as the assay's thermal cycling protocol involved 40 cycles, Ct 37 was the latest $\mathrm{Ct}$ value where the above requirement would be possible to meet. Before scoring any given reaction negative, acceptable PCR conditions were always confirmed by verifying that the $\mathrm{Ct}$ values and the shape of the amplification curves of the internal amplification controls were acceptable. If the assay provided a cross-reaction; that is, a positive result for a bacterial target that was not reported to be present in the culture isolate by the provider of the isolate, the cross-reaction was always confirmed by repeating the analysis for the sample (a total of 9 cases; see below). Finally, a negative control (sterile water) was included in every real-time PCR run and each multiplex PCR reaction, for confirmation that cross-contaminations had not occurred in the laboratory.

\section{DNA Sequencing}

In cases where the assay provided discordant results when compared with the initial species identification (a total of 9 cases), part of the $16 \mathrm{~S}$ rRNA gene (711 bp) was sequenced from the isolates to confirm or to refute such false positive or negative results. The following universal primers were used for amplifying the sequenced $16 \mathrm{~S}$ rRNA fragments: F-CGCTGGCGGCGTGCCTAATA$\mathrm{CA}$ and R-CCGCCTTCGCCACCGGTGTTCCTC. The PCR products were purified using the QIAquick PCR purification kit (Qiagen GmbH, Hilden, Germany) and submitted for sequencing to Eurofins MWG (Martinsried, Germany). Satisfactory quality of the sequencing reads was confirmed by visual inspection of the electropherograms. The nucleotide sequences were compared with GenBank (Benson et al., 2008) sequences using the Basic Local Alignment Search Tool (BLAST; Altschul et al., 1990). Pair-wise sequence alignments were performed using the Clustal algorithm implemented in the program DNA Star (DNASTAR Inc., Madison, WI).

\section{Sensitivity and Specificity Calculations}

The sensitivity and specificity of the assay were calculated for each target using the following formulas (Martin, 1984):

Sensitivity $\%=$ [number of true positive samples $/$

(number of true positive samples

+ number of false negative samples) $] \times 100$

Specificity $\%=$ [number of true negative samples /

(number of true negative samples

+ number of false positive samples) $] \times 100$

\section{RESULTS}

When considering the bacteria originating from clinical bovine mastitis $(\mathrm{n}=454)$, the real-time PCR assay provided correct identification results for all isolates; that is, the analytical specificity and sensitivity were $100 \%$ for all bacterial targets (Table 1). With the entire 


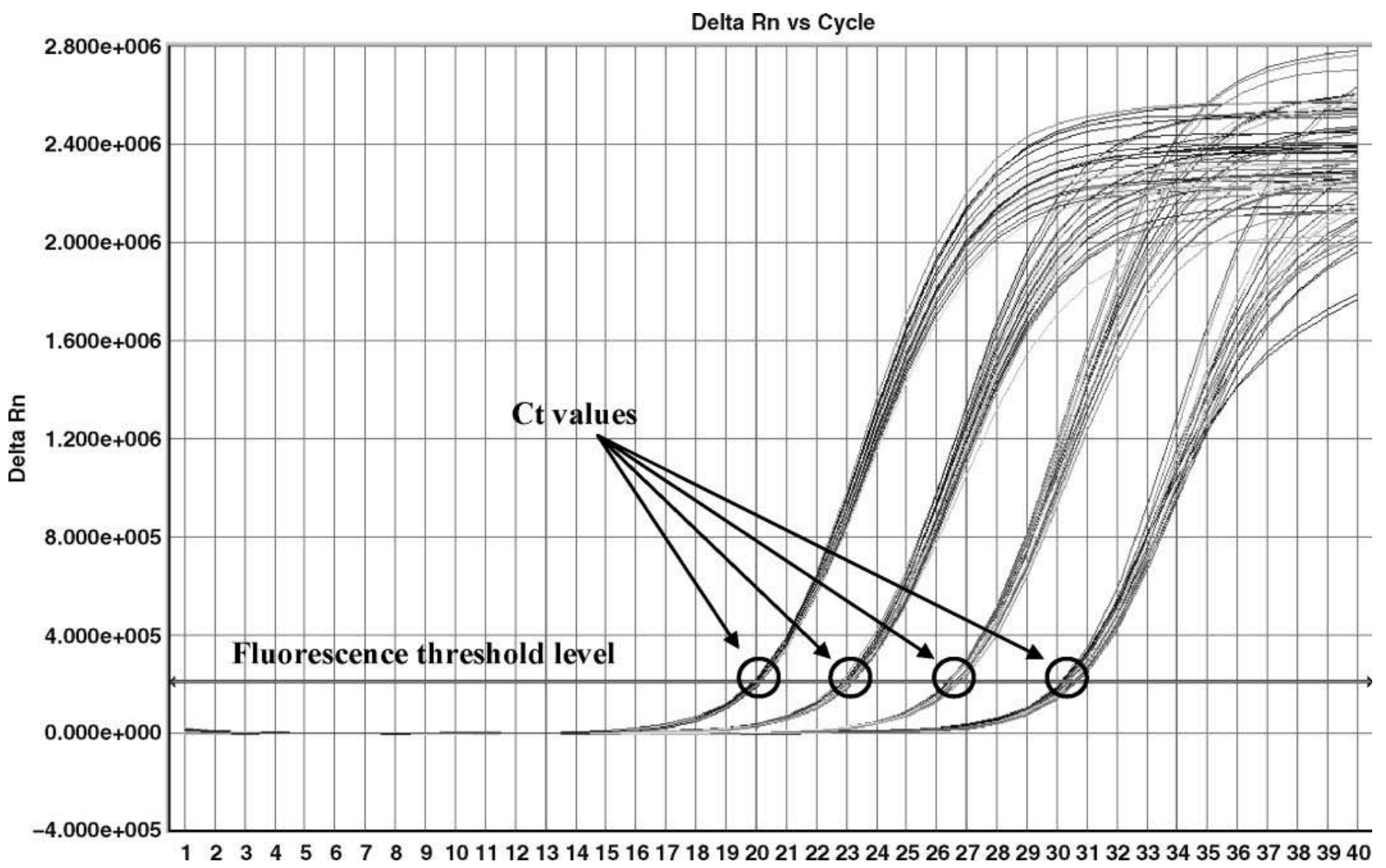

Figure 1. An internal amplification control (IAC), composed of a 93-bp fragment of lambda-DNA, is included in the Primer Mixes 1, 2, 3, and 4 of the PathoProof Mastitis PCR Assay in $10^{6}, 10^{5}, 10^{4}$, and $10^{3}$ copies, respectively. Illustrated are IAC amplification curves obtained from the 4 real-time PCR reactions of the assay for 20 different bacterial culture samples. IAC amplification curves should obtain a shape characteristic of an acceptable PCR reaction, and obtain Ct values approximately 3.3 cycles apart between the $10 \times$ dilutions in lambda-DNA copy numbers, as illustrated here.

collection of 643 bacterial isolates from bovine mastitis and isolates of companion animal and human origin, the assay provided 634 correct bacterial identifications. No false-negative results were obtained. However, 4 Strep. pyogenes samples (human origin), 1 Strep. salivarius strain (human origin) and 1 Strep. sanguis isolate (human origin) were identified as Strep. uberis, and 3 Shigella spp. isolates (human origin), were identified as $E$. coli. Sequencing of the $16 \mathrm{~S}$ rRNA gene from these 9 isolates and sequence alignments against GenBank data confirmed these false-positive results by indicating that the most probable sequence matches were the species identified by the culture providers (GenBank accession numbers FJ 168527-FJ 168535). Consequently, for the entire data set, including the clinical human and dog samples, the test had an analytical sensitivity of $100 \%$ for all target bacteria and specificity of $99.0 \%$ for Strep. uberis, $99.5 \%$ for E. coli and $100 \%$ for all other target bacteria (Table 1).

The real-time PCR assay provided positive results for all of the $72 \beta$-lactamase positive isolates and negative results for all $77 \beta$-lactamase negative isolates. Hence, it is concluded that both the analytical specificity and sensitivity of the assay in $\beta$-lactamase detection was $100 \%$ (Table 1).

The amplification curves and the $\mathrm{Ct}$ values of the internal amplification controls were acceptable for all samples and reactions, as exemplified in Figure 1, confirming that possible PCR inhibitors in the samples, or human errors in the reaction set-up, were not influencing the results. The variation in $\mathrm{Ct}$ values, indicated by the standard deviation bars in Figure 2, was caused by variation in bacterial DNA quantity between the culture isolates included in the study. Nevertheless, the mean Ct values across all of the true positive samples for the different bacterial targets ranged from 16.6 (blaZ) to 27.7 (S. marcescens), being well below the upper $\mathrm{Ct}$ value $(\mathrm{Ct}=37)$ for scoring a reaction positive (Figure 2). The low Ct values, apparent from Figure 2, also indicated that sufficiently high amount of bacterial DNA was used for the reactions for triggering potential cross-reactions. 


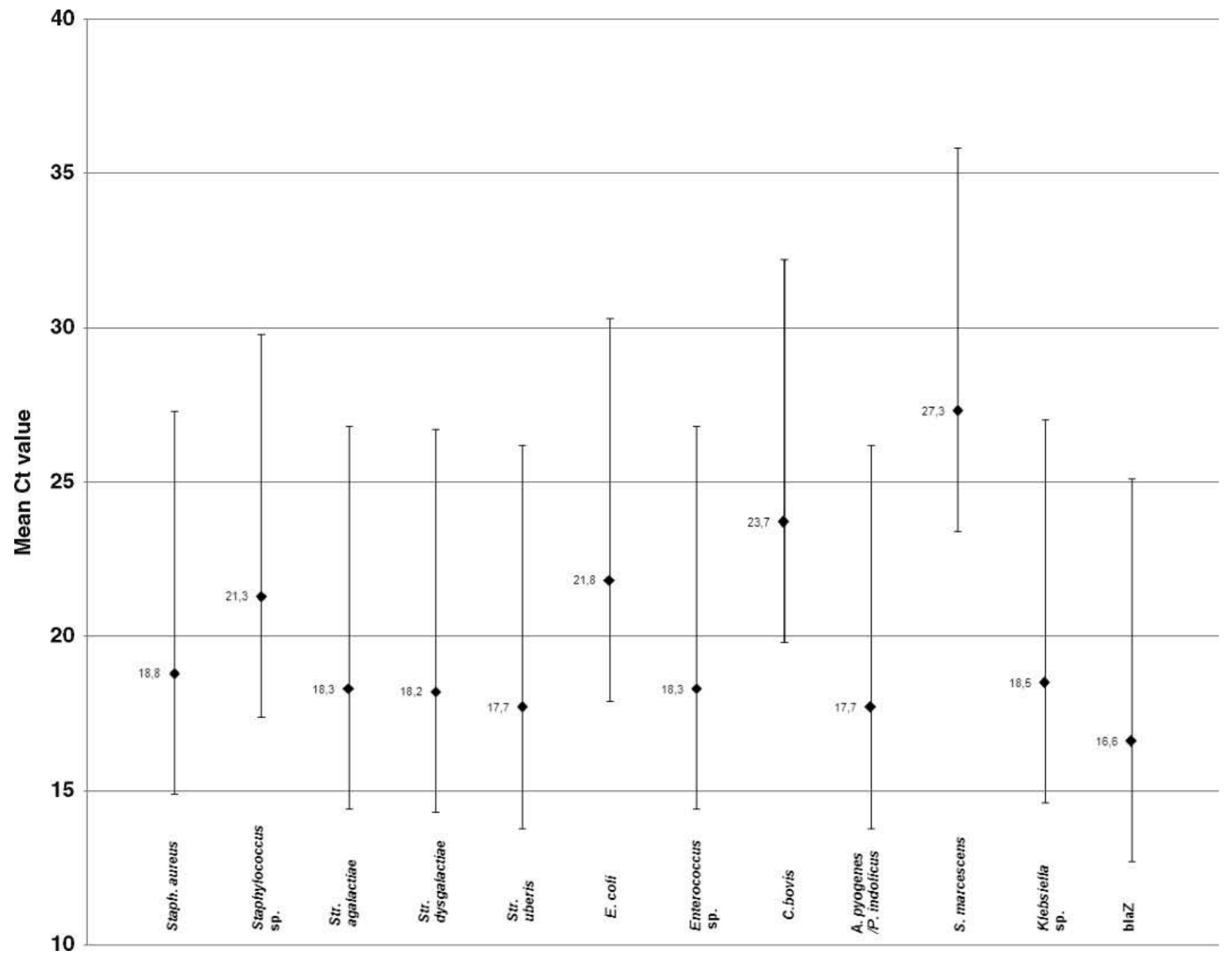

Figure 2. Mean cycle threshold $(\mathrm{Ct})$ values and their standard deviations for all of the true positive samples used in the study, including the culture isolates originating from bovine mastitis, human, and companion animal samples. The Ct value provided by the PathoProof Mastitis PCR Assay reflects bacterial quantity in the sample. Variation in the mean Ct values and the standard deviations indicate that the bacterial cultures had variation in their bacterial quantity. The cut-off $\mathrm{Ct}$ value for scoring a sample positive for a bacterial target is $\mathrm{Ct}=37$.

\section{DISCUSSION}

This study is the first to report on the specificity and sensitivity trials of a commercial real-time PCR assay for identification of all major pathogens responsible for bovine IMI. The results showed $100 \%$ specificity (no false positives) and $100 \%$ sensitivity (no false negatives) in identification of bacteria from a substantial collection of isolates originating from bovine mastitis. High specificity and sensitivity results for all target bacteria of the assay are especially noteworthy because the cultures were collected from a broad geographical region, increasing the probability of obtaining a genetically diverse representation of strains, as well as providing evidence that the assay has potential for high accuracy across different countries. The results for $\beta$-lactamase gene detection were also good, with $100 \%$ concordance with the PCR test used as a gold standard in an earlier study (Pitkälä et al., 2007).

Although the PathoProof Mastitis PCR Assay can be used with mastitic milk samples, the current study used culture isolates obtained from commercial and noncommercial collections. Isolates available from the culture collections were characterized to their species or group levels as accurately as possible (e.g., based on DNA sequencing) and provide a necessary matrix for a primary specificity and sensitivity study in a situation where a reliable, routinely used gold standard method 
is lacking, as is the case in diagnosing IMI (e.g., Pitkälä et al., 2005). The results presented here unambiguously confirm the accuracy of the real-time PCR primers and probes employed by the assay, and form the basis for field performance trials against bacterial culture methods routinely used with mastitic milk samples.

Accurate identification of many mastitis-causing species based on the conventional bacteriological methods is challenging, subjective, and requires extensive experience from the operator. For example, distinction between esculin-hydrolyzing streptococci and enterococci, or separation of E. coli and K. oxytoca is difficult without time-consuming complementary tests (Fortin et al., 2003). Consequently, results from different laboratories vary and false identifications of the common mastitis pathogens are possible (Pitkälä et al., 2005). Real-time PCR offers an inherent benefit to this end; well-designed internal controls and predefined threshold $\mathrm{Ct}$ values for scoring positive and negative results allow fully objective interpretation of data (Bustin, 2004). Partly for this reason, real-time PCR has become the mainstream technology and the standard method in many diagnostic applications for human pathogens (Mackay, 2004). Assuming that proper equipment is in place, analytical specificity and sensitivity results similar to those shown in the present study should be possible to achieve in any routine bacteriological laboratory and regardless of the operators' experience.

Conventional bacterial culturing is relatively slow to perform, as incubation of primary cultures often requires $48 \mathrm{~h}$ (or up to $72 \mathrm{~h}$ ) to complete, and additional confirmation tests are also time-consuming (National Mastitis Council, 1999). To overcome this problem, diagnostic culture kits allowing faster results have previously been introduced for mastitis testing, but their diagnostic accuracy has been limited (Leslie and Dingwell, 2002; Simojoki et al., 2008). The PathoProof Mastitis PCR Assay does not require a culture step and the total analysis time is 3 to $4 \mathrm{~h}$. In clinical mastitis, such rapid results should shorten the total duration of treatment, improve the therapeutic outcome, and decrease unnecessary use of antimicrobials (Pyörälä, 2002; Barkema et al., 2006).

In conventional culturing, approximately 25 to $50 \%$ of all samples from mastitis harbor no bacterial growth (Makovec and Ruegg, 2003; Bradley et al., 2007; Koivula et al., 2007). One explanation for these samples is that they contain anaerobic bacteria, which do not grow on standard media, or facultatively anaerobic species, for example $A$. pyogenes or $C$. bovis, which grow slowly or may require additional growth factors (Makovec and Ruegg, 2003; Pitkälä et al., 2005). Inflammation of the mammary gland, inhibitory metabolic products of bacteria, or unfavorable conditions during sample transportation could also decrease the viability of the mastitis bacteria (Dinsmore et al., 1992). As the real-time PCR test is based on identification of bacterial DNA, it is not dependent on the viability of the bacteria to grow in a laboratory environment, and can also detect growth-inhibited or dead bacteria. This possibility may also enable the application of integrating IMI testing into milk monitoring and dairy herd improvement schemes using bronopol-preserved milk. In the future, high SCC readings (high SCC is thought to be primarily caused by mastitis) could be coupled with bacterial identification from the same preserved samples taken from milk metering devices.

In conclusion, the real-time PCR assay shows excellent analytical specificity and sensitivity and holds much promise as a routine tool in diagnosing mastitis pathogens. This study provides the basis for evaluating the assay's diagnostic performance in field trials against conventional bacterial culture methods using milk samples from cows with clinical and subclinical mastitis. The field trials will eventually help to demonstrate whether the assay can be implemented in routine mastitis testing schemes. The real-time PCR test has added reagent and instrument costs in comparison with the conventional bacterial-culture-based methods. The added costs must be considered, in connection with all of the technical benefits provided by the assay, when making decisions on implementation of the PathoProof Mastitis PCR Assay in routine mastitis testing programs.

\section{REFERENCES}

Altschul, S. F., W. Gish, W. Miller, E. W. Myers, and D. J. Lipman. 1990. Basic local alignment search tool. J. Mol. Biol. 215:403410.

Barkema, H. W., Y. H. Schukken, and R. N. Zadoks. 2006. The role of cow, pathogen, and treatment regimen in the therapeutic success of bovine Staphylococcus aureus mastitis. J. Dairy Sci. 89:18771895

Benson, D. A., I. Karsch-Mizrachi, D. J. Lipman, J. Ostell, and D. L. Wheeler. 2008. GenBank. Nucleic Acids Res. 36:D25-D30.

Bradley, A. J., K. A. Leach, J. E. Breen, L. E. Green, and M. J. Green. 2007. Survey on the incidence and aetiology of mastitis on dairy farms in England and Wales. Vet. Rec. 160:253-258.

Bustin, S. A. 2004. Quantification of nucleic acids by PCR. Pages 5-46 in An A-Z Manual of Quantitative PCR. IUL Press, La Jolla, CA.

Dinsmore, R. P., P. B. English, R. N. Gonzalez, and P. M. Sears. 1992. Use of augmented cultural techniques in the diagnosis of the bacterial cause of clinical bovine mastitis. J. Dairy Sci. 75:27062712 .

Fortin, M., S. Messier, J. Paré, and R. Higgins. 2003. Identification of catalase-negative, non-beta-hemolytic, gram-positive cocci isolated from milk samples. J. Clin. Microbiol. 41:106-109.

Gillespie, B. E., and S. P. Oliver. 2005. Simultaneous detection of mastitis pathogens, Staphylococcus aureus, Streptococcus uberis, and Streptococcus agalactiae by multiplex real-time polymerase chain reaction. J. Dairy Sci. 88:3510-3518. 
Halasa, T., K. Huijps, O. Østerås, and H. Hogeveen. 2007. Economic effects of bovine mastitis and mastitis management. Vet. Q. $29: 18-31$

Hogan, J. S., R. N. Gonzalez, R. J. Harmon, S. C. Nickerson, S. P. Oliver, J. W. Pankey, and K. L. Smith. 1999. Laboratory Handbook on Bovine Mastitis. National Mastitis Council, Madison, WI.

Koivula, M., E. A. Mäntysaari, A. Pitkälä, and S. Pyörälä. 2007. Distribution of bacteria and seasonal and regional effects in a new database for mastitis pathogens in Finland. Acta Agric. Scand. A 57:89-96.

Leslie, K., and R. Dingwell. 2002. Mastitis control: Where are we and where are we going? Pages 370-382 in Recent Developments and Perspectives in Bovine Medicine. Kaske, M., H. Scholz, and M. Höltershinken, ed. Keynote Lectures in XXII World Buiatrics Congress, Hannover, Germany. Hildesheimer Druck und VerlagGmbH, Hildesheim, Germany.

Mackay, I. M. 2004. Real-time PCR in the microbiology laboratory. Clin. Microbiol. Infect. 10:190-212.

Makovec, J. A., and P. L. Ruegg. 2003. Results of milk samples submitted for microbiological examination in Wisconsin from 1994 to 2001. J. Dairy Sci. 86:3466-3472.

Martin, S. W. 1984. Estimating disease prevalence and the interpretation of screening test results. Prev. Vet. Med. 2:463-472.

National Mastitis Council. 1996. Current Concepts of Bovine Mastitis. 4th ed. National Mastitis Council, Madison, WI.

National Mastitis Council. 1999. Laboratory Handbook on Bovine Mastitis. National Mastitis Council, Madison, WI.

National Mastitis Council. 2004. Microbiological Procedures for the Diagnosis of Bovine Udder Infection and Determination of Milk Quality. 4th ed. National Mastitis Council, Madison, WI.

Phuektes, P., G. F. Browning, G. Anderson, and P. D. Mansell. 2003 Multiplex polymerase chain reaction as a mastitis screening test for Staphylococcus aureus, Streptococcus agalactiae, Streptococcus dysgalactiae and Streptococcus uberis in bulk milk samples. J. Dairy Res. 70:149-155.

Pitkälä, A., V. Gindonis, H. Wallin, and T. Honkanen-Buzalski. 2005. Interlaboratory proficiency testing as a tool for improving performance in laboratories diagnosing bovine mastitis. J. Dairy Sci. $88: 553-559$

Pitkälä, A., L. Salmikivi, P. Bredbacka, A.-L. Myllyniemi, and M. T. Koskinen. 2007. Comparison of tests for detection of $\beta$-lactamaseproducing staphylococci. J. Clin. Microbiol. 45:2031-2033.

Pyörälä, S. Trends and advances in mastitis therapy. 2002. Pages 360-368 in Recent Developments and Perspectives in Bovine Medicine. Kaske, M., H. Scholz, \& M. Höltershinken, eds. Keynote Lectures in XXII World Buiatrics Congress, Hannover, Germany, Hildesheimer Druck und Verlag-GmbH, Hildesheim, Germany.

Riffon, R., K. Sayasith, H. Khalil, P. Dubreuil, M. Drolet, and J. Lagace. 2001. Development of a rapid and sensitive test for identification of major pathogens in bovine mastitis by PCR. J. Clin. Microbiol. 39:2584-2589.

Simojoki, H., S. Erkkilä, A. Pitkälä, and S. Pyörälä. 2008. A pilot study on the bacteriological diagnostics of bovine mastitis carried out by Finnish veterinarians. Page 61 in Proc. 25th Congress of World Buiatrics Association, Budapest, Hungary.

Tenhagen, B.-A., G. Köster, J. Wallmann, and W. Heuwieser. 2006. Prevalence of mastitis pathogens and their resistance against antimicrobial agents in dairy cows in Brandenburg, Germany. J. Dairy Sci. 89:2542-2551.

Watts, J. L., and R. J. Yancey Jr. 1994. Identification of veterinary pathogens by use of commercial identification systems and new trends in antimicrobial susceptibility testing of veterinary pathogens. Clin. Microbiol. Rev. 7:346-356. 